\title{
Supporting newly qualified dental therapists into practice: a longitudinal evaluation of a foundation training scheme for dental therapists (TFT)
}

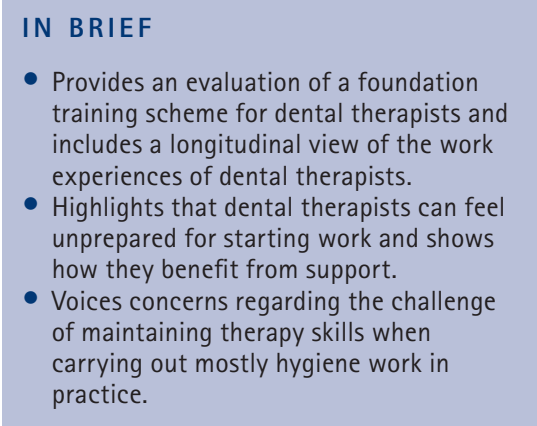

- Provides an evaluation of a foundation training scheme for dental therapists and includes a longitudinal view of the work experiences of dental therapists.

Highlights that dental therapists can feel rk and shows

of maintaining therapy skills when practice.

\author{
A. D. Bullock, ${ }^{* 1}$ E. Barnes, ${ }^{1}$ H. C. Falcon ${ }^{2}$ and K. Stearns ${ }^{2}$
}

Objectives Focused on the dental therapists foundation training (TFT) scheme run by the Postgraduate Dental Deaneries of Oxford and Wessex (NHS Education South Central - NESC) the objectives were (1) to evaluate the TFT 2010/11 scheme, identifying strengths, areas for development and drawing comparisons with the 2009 evaluation; and (2) to follow-up previous cohorts, reporting current work and retrospective reflections on the scheme. Methods Data were collected from 2010/11 ('current') trainees $(n=10)$ through group discussion, questionnaire and portfolio extracts. Eleven past-trainees from 2008/09 and 2009/10 took part in a structured telephone interview or responded to questions via e-mail. Results Data from 2011 consolidated that collected earlier. The scheme was highly valued. Current participants thought the scheme should be mandatory and all past-participants would recommend it to others. Trainees attributed an increase in confidence and ability in their clinical skills to participation in TFT. Current trainees' concerns about finding therapy work were echoed in past-participants' post-scheme employment. Conclusions At the point of qualification, trainees do not feel well-prepared for starting work as dental therapists. Opportunity to develop confidence and skills in a supportive environment is a key benefit of the scheme. Maintaining ability in the full range of duties requires continued use of skills and the opportunity to do this remains an ongoing challenge.

\section{INTRODUCTION}

\section{Context}

Only a small portion of dental treatment is complex and there is considerable scope to delegate routine treatments to dental therapists. ${ }^{1}$ In July 2002 the General Dental Council (GDC) allowed dental therapists to work in general dental practice and extended their duties. The permitted duties of each dental registrant group have been set out by the GDC in their Scope of practice document. ${ }^{2}$

Although there is significant capacity to use therapists for much routine dentistry, thus releasing dentists for more complex

\footnotetext{
${ }^{1}$ Cardiff Unit for Research and Evaluation in Medical and Dental Education (CUREMeDE), Cardiff University School of Social Sciences, Glamorgan Building, King Edward VII Avenue, Cardiff, CF10 3WT; ${ }^{2}$ Oxford and Wessex Deaneries (NHS Education South Central), The Triangle, Roosevelt Drive, Headington, Oxford, OX3 7XP *Correspondence to: Alison Bullock Email: bullockad@cardiff.ac.uk
}

\section{Online article number E20}

Refereed Paper - accepted 7 December 2012

DOI: 10.1038/sj.bdj.2013.425

${ }^{\circ}$ British Dental Journal 2013; 214: E20 treatments, ${ }^{1}$ there are considerable barriers to developing and maintaining the skills of dental therapists. ${ }^{3,4}$ Brocklehurst and Tickle $^{5}$ identified four factors affecting skill mix in dentistry: regulation, professional culture, societal (patient acceptability) and structural influences (including remuneration, infrastructure and training). Bullock and Firmstone ${ }^{6}$ organised such factors into three operational levels: macro (including regulation, workforce profile, commissioning frameworks and demand for services), meso (payment systems in practices and premises capacity) and micro (lead dentist's knowledge, therapist motivations, patient attitudes). They argued that education and training plays a central role in realising skill-mix change.

\section{The TFT scheme}

Introduced in 2008, the Oxford and Wessex Postgraduate Dental Deanery's dental therapists' foundation training (TFT) scheme was the first in England. In its first year of operation the scheme was evaluated. ${ }^{7}$ TFT runs for 12 months. The main features of
Table 1 The study day programme (from the scheme handbook 2011-12)

Introduction to the TFT year; residential with TFT trainers (two-days)

Dental radiography in practice;

clinical photography

FGDP key skills support session; introduction to professional development planning; dealing with medical emergencies

FGDP key skills support session; communication skill for the dental team; (joint with DF1s)

Diagnosis and treatment planning in periodontics (joint session with DF1s)

Practical session: management of the grossly carious primary tooth

Chicago International Dental Conference (joint with DF1s) (one week)

Practical session: assessment and treatment of the traumatised anterior tooth

Modern caries management (joint with DF1s)

Oral mucosal disease; child protection

Dental protection society; General Dental Council fitness to practice case hearing

Interview techniques and $\mathrm{CV}$ writing; case presentations

Financial planning and career development for the dental therapist; exit interviews 
TFT remain unchanged since the original programme and include training practices with an appointed trainer, a study-day programme (Table 1), the use of a learning portfolio and workplace-based assessments (direct observation of procedural skills - DOPS, and case-based discussion - CbD). Modifications to the scheme have been made to the title (from dental therapists' vocational training - TVT - to TFT); the process for matching trainees and practices; number of study days (increased); content (reduction in the number of FGDP key skills modules and inclusion of two audits - record-keeping and radiography); and additional assessments (an early stage peer review, 'ADEPT' - a dental evaluation of performance tool, and patient assessment questionnaires - PAQs). ${ }^{8}$

Trainers are recruited by open competition from NHS dental practices within the geographical area. The scheme draws on dental practices across the whole NHS South Central area (Berkshire, Buckingham, Oxfordshire, Milton Keynes, Hampshire and the Isle of Wight). Practices in Northamptonshire were initially included but funding is now no longer available for outside areas.

TFT adopts a part time model: trainees work in the training practice as dental therapists for three days a week. Typically they work as hygienists for the other days. Trainers provide at least 20 tutorials during the year, in protected time during normal working hours. Trainers are required to attend a training-the-trainers course. They receive a small, practice reimbursement grant and the Deanery pays half the therapist's salary.

In many respects the TFT scheme is similar to the Introduction to Practice (ITP) scheme for dental therapists run by the Wales Deanery. Both combine part time placement in a training practice with a study day programme (covering similar content) and use learning portfolios. Expectations of the in-practice trainer are greater in TFT and more workplace-based assessments are included. Unique features of the TFT scheme include attendance at an international dental conference held in Chicago, FGDP key skills modules and some joint sessions with dental foundation trainees.

\section{AIMS}

The purpose of this study was to provide follow-on to the evaluation of the dental

Table 2 Changes in confidence from graduation to end of TFT for 16 aspects of work (two cohorts)

Change $(2010 / 11 ; 10$ participants) Change (2008/09; 9 participants)

\begin{tabular}{|c|c|c|c|c|c|c|c|c|c|c|c|c|c|c|}
\hline Aspects of work & -1 & 0 & 1 & 2 & 3 & 4 & Total & -1 & 0 & 1 & 2 & 3 & 4 & Total \\
\hline Paediatric dentistry & 0 & 0 & 1 & 5 & 4 & 0 & 23 & 0 & 2 & 1 & 4 & 1 & 1 & 16 \\
\hline Clinical judgement & 0 & 0 & 1 & 6 & 3 & 0 & 22 & 0 & 0 & 2 & 6 & 1 & 0 & 17 \\
\hline Restorative dentistry & 0 & 0 & 2 & 5 & 3 & 0 & 21 & 0 & 0 & 3 & 5 & 1 & 0 & 16 \\
\hline $\begin{array}{l}\text { Investigation } \\
\text { and referral }\end{array}$ & 0 & 1 & 3 & 5 & 1 & 0 & 16 & 0 & 1 & 2 & 5 & 1 & 0 & 15 \\
\hline Legislation & 0 & 1 & 3 & 6 & 0 & 0 & 15 & 0 & 2 & 3 & 2 & 2 & 0 & 13 \\
\hline $\begin{array}{l}\text { Clinical assessment } \\
\text { and examination skills }\end{array}$ & 0 & 1 & 4 & 4 & 1 & 0 & 15 & 0 & 1 & 4 & 4 & 0 & 0 & 12 \\
\hline Communication skills & 0 & 3 & 4 & 2 & 0 & 1 & 12 & 0 & 1 & 2 & 4 & 2 & 0 & 16 \\
\hline Preventative dentistry & 0 & 2 & 5 & 2 & 1 & 0 & 12 & 0 & 1 & 3 & 3 & 2 & 0 & 15 \\
\hline Medical record keeping & 0 & 3 & 2 & 5 & 0 & 0 & 12 & 1 & 0 & 5 & 3 & 0 & 0 & 10 \\
\hline History taking & 0 & 4 & 1 & 5 & 0 & 0 & 11 & 0 & 1 & 5 & 3 & 0 & 0 & 11 \\
\hline Medical emergencies & 0 & 2 & 5 & 3 & 0 & 0 & 11 & 0 & 2 & 5 & 1 & 1 & 0 & 10 \\
\hline Dental pathology & 0 & 2 & 6 & 2 & 0 & 0 & 10 & 0 & 1 & 6 & 2 & 0 & 0 & 10 \\
\hline Professionalism & 0 & 3 & 5 & 2 & 0 & 0 & 9 & 0 & 0 & 5 & 3 & 1 & 0 & 14 \\
\hline Pharmacology & 0 & 1 & 9 & 0 & 0 & 0 & 9 & 1 & 1 & 6 & 1 & 0 & 0 & 7 \\
\hline Cross-infection control & 0 & 5 & 4 & 1 & 0 & 0 & 6 & 0 & 2 & 2 & 5 & 0 & 0 & 12 \\
\hline $\begin{array}{l}\text { Treating patients under } \\
\text { conscious sedation }\end{array}$ & 1 & 7 & 0 & 2 & 0 & 0 & 3 & 0 & 5 & 4 & 0 & 0 & 0 & 4 \\
\hline
\end{tabular}

therapists foundation training (TFT) scheme in its first year of operation (2008/09). ${ }^{7}$ This evaluation, commissioned by the Oxford and Wessex Deaneries, updates that earlier evaluation, drawing comparison between the 2010/11 and 2008/09 cohorts and providing a longitudinal review from previous cohorts, reporting on their current work and retrospective reflections on the value of the scheme.

\section{METHOD}

The study was undertaken between May and November 2011. To allow comparison, the questionnaire as used in the original evaluation was distributed face-to-face at the final study day and was completed by all ten 2010/11 trainees. It was preceded by a group discussion. Group responses were noted on a flip chart. Separate to the questionnaire, therapists also rated their level of confidence at the end of TFT for a given list of specific clinical activities. Extracts from the course portfolios were photocopied, including self-ratings of confidence at the start of TFT. Information on treatments performed for months nine and ten was also extracted.
Past-trainees who had completed the scheme in August 2009 or 2010 were sent a written invitation to be interviewed. Those consenting were interviewed via telephone. Interviews explored participant's current role, work experience, aspirations and retrospective reflections on the value of the scheme. All interviews were digitally recorded and transcribed. Reminders were sent out three times to all non-respondents offering the option of completing the questions via e-mail.

Research ethics approval was obtained from Cardiff University, School of Postgraduate Medical and Dental Education Research Ethics Committee (11/05/11).

\section{RESULTS}

\section{Experience}

The average number of units of dental activity (UDAs) for those on the TFT scheme was 121 in month nine, with a range of 61-234. The average for month ten was 145 UDAs, range 39-424. Comparable figures from 2009 were month nine: 120 , range $32-186$; month ten: 138, range 64-262. Although the number of treatments undertaken by 
Table 3 Changes in confidence from graduation to end of TFT for specific clinical activities (2009/2011)

\begin{tabular}{|c|c|c|c|c|c|c|c|c|c|c|c|c|c|c|c|c|}
\hline \multirow[b]{2}{*}{ Specific clinical experience } & \multicolumn{10}{|c|}{ Change (2010/11; 10 participants) } & \multicolumn{6}{|c|}{ Change (2008/09; 9 participants) } \\
\hline & -3 & -2 & -1 & 0 & 1 & 2 & 3 & 4 & 5 & Total & -1 & 0 & 1 & 2 & 3 & Total \\
\hline Extractions & 0 & 0 & 1 & 2 & 1 & 1 & 3 & 1 & 1 & 20 & & 1 & 2 & 3 & 3 & 17 \\
\hline Pulpotomy $y^{* * * *}$ & 0 & 0 & 0 & 1 & 1 & 3 & 4 & 0 & 0 & 19 & \multicolumn{5}{|c|}{ Mean } & 13 \\
\hline Amalgam restorations & 0 & 0 & 0 & 1 & 3 & 3 & 3 & 0 & 0 & 18 & \multicolumn{5}{|c|}{ Mean } & 14 \\
\hline Composites - posterior** & 0 & 0 & 0 & 0 & 6 & 1 & 2 & 1 & 0 & 18 & \multicolumn{5}{|c|}{ Mean } & 12 \\
\hline Local anaesthetic & 0 & 0 & 0 & 0 & 6 & 2 & 2 & 0 & 0 & 16 & \multicolumn{5}{|c|}{ Mean } & 12 \\
\hline Composites - anterior* & 0 & 0 & 0 & 1 & 4 & 4 & 1 & 0 & 0 & 15 & \multicolumn{5}{|c|}{ Mean } & 14 \\
\hline Dental/oral health education* & 0 & 0 & 0 & 1 & 6 & 2 & 1 & 0 & 0 & 13 & 1 & 3 & 2 & 1 & 1 & 6 \\
\hline Supragingival debridement & 0 & 0 & 0 & 2 & 6 & 1 & 0 & 1 & 0 & 12 & 2 & 5 & 0 & 2 & 0 & 2 \\
\hline Impressions & 0 & 0 & 0 & 3 & 3 & 4 & 0 & 0 & 0 & 11 & 1 & 3 & 2 & 3 & 0 & 7 \\
\hline Subgingival debridement & 0 & 0 & 0 & 2 & 5 & 3 & 0 & 0 & 0 & 11 & 2 & 4 & 1 & 1 & 1 & 4 \\
\hline $\begin{array}{l}\text { Preventive resin restorations } \\
\text { (PRRs) }\end{array}$ & 0 & 0 & 0 & 6 & 5 & 1 & 1 & 0 & 0 & 10 & 0 & 3 & 1 & 5 & 0 & 11 \\
\hline Radiographs & 0 & 0 & 0 & 3 & 5 & 2 & 0 & 0 & 0 & 9 & 0 & 0 & 4 & 4 & 1 & 15 \\
\hline Intra/extra oral assessment ${ }^{*}$ & 0 & 0 & 0 & 4 & 5 & 0 & 1 & 0 & 0 & 8 & 1 & 6 & 0 & 1 & 0 & 1 \\
\hline Fissure sealants & 0 & 0 & 0 & 5 & 3 & 2 & 0 & 0 & 0 & 7 & 0 & 3 & 6 & 0 & 0 & 6 \\
\hline $\begin{array}{l}\text { Recording indices } \\
\text { and monitoring disease }\end{array}$ & 0 & 0 & 2 & 2 & 5 & 1 & 0 & 0 & 0 & 5 & 1 & 5 & 2 & 1 & 0 & 3 \\
\hline Stainless steel crowns* & 1 & 1 & 0 & 3 & 3 & 2 & 0 & 0 & 0 & 2 & 0 & 1 & 4 & 3 & 0 & 10 \\
\hline
\end{tabular}

each of the dental therapists on the scheme varied considerably, there was commonality in terms of treatment types with therapists most frequently carrying out restorations and scaling.

\section{Confidence and skills}

Participants were motivated to enrol on the scheme by desire to enhance confidence and broaden clinical experience. Motives in 2011 were unchanged from 2009.

In an attempt to assess change in level of confidence from graduation to the end of TFT for general aspects of their work the therapists were asked to rate their confidence level (on a six-point scale) at these two points. Table 2 shows the change in ratings for each respondent (ranging from one to four) and an aggregate of the changed ratings (total) across the group as a whole. Data from 2009 is included for comparison.

The greatest reported increases in confidence were shown for paediatric dentistry, clinical judgement and restorations. These aspects also attracted most confidence gain in 2009 although total scores cannot be directly compared because there was an additional trainee in 2010/11. Similarity between the years is also notable for the aspect attracting least change in confidence (treating patients under conscious sedation). However, there were also differences, in particular for cross-infection control where confidence gains reported in 2011 were less than those reported in 2009.

Separate to the questionnaire, therapists were asked to rate their level of confidence at the end of TFT for a given list of specific clinical activities. These responses were compared to their self-ratings, extracted (with permission) from their portfolios, which were given at the start of TFT (that is, at graduation). A summary of the changes in confidence is shown in Table 3, which also includes data from the 2008/09 evaluation. The portfolios had been amended since the 2008/09 data collection. Fewer items were listed in the 2010/11 portfolio. Where a single item in the more recent version of the portfolio was sub-divided in the earlier version, an average change score was calculated. For example, the 2008/09 portfolio listed 'pulpotomy vital' and 'pulpotomy non vital'. The change figures were 15 and 11 points. These are given as a mean of 13 for 'pulpotomy' in the table. For amalgam restorations and composites, different classes were listed in the earlier portfolio that also distinguished between 'local inferior dental block' and 'local infiltration' anaesthesia.

Looking at the changes in confidence of the 2010/11 cohort, extractions showed the highest improvement in confidence scores with one participant reporting a five-point increase, one reporting four and three reporting three. Pulpotomies showed the second largest increase in confidence: eight out of the ten of the 2010/11 cohort reported an increase of between one and three points. The results were little changed from 2009. For the 2010/11 cohort, the lowest increase in confidence was for stainless steel crowns, recording indices and monitoring disease. There were some differences at the bottom of the table for the 2008/09 cohort where the aggregate lowest ratings were shown for intra/extra oral assessment and supragingival debridement. 


\section{Views on the TFT scheme}

Trainees' rated their level of agreement with 15 statements on a six-point scale (where one $=$ strongly disagree and six $=$ strongly agree). Table 4 provides a summary of the results and for comparison includes data from the 2008/09 evaluation.

Overall, all ten 2011 respondents agreed that: the scheme should be mandatory for all new graduates (as indicated by a rating of four or more, statement \#1); the trainer provided good in-practice support (\#2); they were keen to use the full range of their therapy skills in their next post (\#3); they felt well integrated into the practice (\#4); and would recommend the scheme to others (\#5). Eight out of ten agreed with statements about the application process (\#7), workplace-based assessments (\#8) and the study days (\#9). Seven agreed with statements about how therapists were matched to practices (\#10), having a CPD plan (\#11) and that the portfolios helped reflection (\#12). However, most were concerned about maintaining their full range of therapy skills (\#6). Responses showed that the trainees did not enjoy the FGDP key skills modules (\#15), did not think them worthwhile (\#13) or felt their undergraduate course had prepared them for working as a therapist (\#14). Views of the 2009 trainees were largely similar. The main difference was for statement \#13 about the value of doing the FGDP key skills modules: seven participants in 2009 agreed with this compared with only three in 2011.

\section{Past-participants}

Eleven past-trainees took part in the evaluation (eight out of nine from 2008/09; three out of ten from 2009/10). All were still working in dentistry. Seven were working as hygienists-therapists doing one to two days of therapy work a week. The other four were working as hygienists. The majority of posts were part time (usually four days a week) working mainly with adults and a mix of NHS and private work. Employment arrangements were complex, typically including a number of part time contracts in different practices. Three pastparticipants reported using the full range of their therapy skills in their current post and a further two claimed to use 'about 70\%?. Two participants were only carrying out hygiene work. The opportunity to practice therapy skills in one case was

\begin{tabular}{|c|c|c|c|c|c|c|c|c|c|c|c|c|}
\hline \multirow{3}{*}{ Statement } & \multicolumn{6}{|c|}{2011} & \multicolumn{6}{|c|}{2009} \\
\hline & \multicolumn{3}{|c|}{$\begin{array}{l}\text { Strongly } \\
\text { disagree }\end{array}$} & \multicolumn{3}{|c|}{$\begin{array}{r}\text { Strongly } \\
\text { agree }\end{array}$} & \multicolumn{4}{|c|}{$\begin{array}{l}\text { Strongly } \\
\text { disagree }\end{array}$} & \multicolumn{2}{|c|}{$\begin{array}{r}\text { Strongly } \\
\text { agree }\end{array}$} \\
\hline & 1 & 2 & 3 & 4 & 5 & 6 & 1 & 2 & 3 & 4 & 5 & 6 \\
\hline $\begin{array}{l}\text { 1. A TFT scheme should be mandatory } \\
\text { for all newly graduated therapists }\end{array}$ & 0 & 0 & 0 & 0 & 3 & 7 & 0 & 0 & 0 & 1 & 3 & 5 \\
\hline $\begin{array}{l}\text { 2. My trainer provided good support } \\
\text { in the practice }\end{array}$ & 0 & 0 & 0 & 0 & 5 & 5 & 0 & 0 & 0 & 3 & 3 & 3 \\
\hline $\begin{array}{l}\text { 3. I am keen to use the full range } \\
\text { of my therapy skills in my next job }\end{array}$ & 0 & 0 & 0 & 1 & 1 & 8 & 0 & 0 & 0 & 2 & 3 & 4 \\
\hline 4. I feel well integrated into the practice & 0 & 0 & 0 & 1 & 1 & 8 & 0 & 0 & 0 & 2 & 3 & 4 \\
\hline $\begin{array}{l}\text { 5. I would recommend this TFT } \\
\text { programme to others }\end{array}$ & 0 & 0 & 0 & 2 & 2 & 6 & 0 & 1 & 0 & 1 & 1 & 6 \\
\hline $\begin{array}{l}\text { 6. I am concerned that I won't be } \\
\text { able to maintain the full range } \\
\text { of my therapy skills }\end{array}$ & 0 & 0 & 2 & 0 & 3 & 5 & 0 & 1 & 0 & 1 & 2 & 5 \\
\hline $\begin{array}{l}\text { 7. The application process for the } \\
\text { TFT scheme was straight forward }\end{array}$ & 1 & 1 & 0 & 1 & 4 & 3 & 0 & 0 & 1 & 3 & 3 & 2 \\
\hline $\begin{array}{l}\text { 8. The workplace based assessments pro- } \\
\text { vided good feedback on my performance }\end{array}$ & 0 & 1 & 1 & 1 & 7 & 0 & 0 & 0 & 0 & 2 & 4 & 3 \\
\hline $\begin{array}{l}\text { 9. The study day programme was } \\
\text { well matched to my learning needs }\end{array}$ & 0 & 0 & 2 & 3 & 4 & 1 & 0 & 0 & 0 & 5 & 3 & 1 \\
\hline $\begin{array}{l}\text { 10. The way therapists were matched } \\
\text { to training practices worked well }\end{array}$ & 1 & 1 & 1 & 0 & 3 & 4 & 1 & 0 & 0 & 1 & 4 & 3 \\
\hline $\begin{array}{l}\text { 11. I have a clear plan for my continuing } \\
\text { professional development (CPD) }\end{array}$ & 0 & 0 & 3 & 1 & 4 & 2 & 0 & 1 & 3 & 4 & 1 & 0 \\
\hline $\begin{array}{l}\text { 12. The learning portfolios helped } \\
\text { me reflect on my progress }\end{array}$ & 0 & 0 & 3 & 3 & 4 & 0 & 0 & 0 & 0 & 4 & 3 & 2 \\
\hline $\begin{array}{l}\text { 13. It was worthwhile doing } \\
\text { the FGDP key skills modules }\end{array}$ & 3 & 2 & 2 & 3 & 0 & 0 & 0 & 1 & 1 & 3 & 2 & 2 \\
\hline $\begin{array}{l}\text { 14. I feel the undergraduate course prepared } \\
\text { me well for starting work as a therapist }\end{array}$ & 1 & 1 & 6 & 0 & 1 & 1 & 0 & 2 & 4 & 1 & 1 & 1 \\
\hline 15. I enjoyed the FGDP key skills modules & 2 & 6 & 1 & 1 & 0 & 0 & 2 & 0 & 4 & 2 & 1 & 0 \\
\hline
\end{tabular}

limited by the employment of a DF trainee (DFT). She explained that:

'My trainer was able to provide me with some therapy work for a few months before he took on a dentist VT [DFT] which reduced my opportunity, so I have since just been doing hygiene with the scope for the offer of therapy in the future if the funding becomes available.' (Trainee 2008/09)

The majority of past-participants wanted to carry out more therapy work although some were happy to continue with their current mix of hygiene and therapy work.

All the past-participants contacted said that they would recommend the scheme to others. They reported that the scheme had enabled them to develop their skills and confidence, both professionally and personally.

'I think it has been invaluable and I wouldn't feel confident to carry out all the treatment I do now if I hadn't completed the course.' (Trainee 2008/09)
It also served to enhance dentists' knowledge of the skills of a dental therapist:

'It should be made compulsory to all students. I think that would promote awareness to dentists as well, to know what we do.' (Trainee 2009/10)

TF trainees also spoke of valuing the support network they had developed with the other trainees.

\section{DISCUSSION}

There is value in undertaking formative evaluations. Recommendations from the first evaluation in 2009 have been addressed and improvements made to the scheme. The more recent evaluation identified further specific recommendations including the need to check the match between the training needs of the participants and the FGDP key modules and giving trainees a better understanding of their potential value

At the point of qualification, trainees did not feel well prepared for starting work as 
dental therapists and the opportunity to develop confidence and skills in a supportive environment is a key benefit of the programme. TFT includes joint sessions with the dental foundation (DF) trainees and the TFT portfolio mirrors the one used in dental foundation training. This serves to signal the importance of TFT and its growing parity with DFT. The 2010/11 group made some constructive suggestions about joint sessions with DF trainees including TF trainees presenting their work to the group.

As was found in the 2009 evaluation, the newly qualified therapists who took part in TFT clearly developed and consolidated their skills and confidence in dental therapy work. The support provided by trainers was rated highly. From the review of activity logs, the average amount of activity increased slightly from 2009. At the time of the evaluation, the UDA was the contract currency in England and Wales. Dental foundation (DF) trainees were expected to complete 1,875 UDAs over the year. Data from the TF trainees suggests that on average they were undertaking an equivalent pro rata amount. ${ }^{7}$ As before, we found wide variation in the numbers of UDAs undertaken by the therapists in different practices. Reasons for this are multifaceted and relate to patient demographics and treatment complexity. As UDAs are related to the complexity of treatment rather than the number of teeth treated, in practice it can be 'harder' to earn UDAs in areas of high treatment (as, for example, the same number of UDAs is earned for treating a patient who needs one restoration as for treating a patient who needs six). Furthermore, treatment times need to be longer for the more challenging and medically compromised patients more commonly seen by dental therapists working in the community dental service. In addition, therapists' UDAs are for treatments only whereas examinations will comprise some of the UDAs for dentists. The UDA as a comparative measure is limited. Trainers should be watchful of the pattern of accumulating experience and mindful of the feedback from the scheme adviser so that trainees get as much opportunity as possible to develop diverse skills.

The ongoing challenge recognised by the trainees was the need to continue to use and maintain their confidence and ability in the full range of duties. This remained an issue for those post-scheme. Four out of the 11 in our sample of past-participants were working as hygienists without any therapy work and several others were concerned about sustaining the full range of their therapy skills. Other studies have also identified this issue. ${ }^{9}$ Finding work as a therapist is not helped by GDPs' relative lack of knowledge about the work of dental therapists. ${ }^{10-13}$ There is a role for further training for dental team leads in better understanding extended duties and skill mix.

Whether the less complex dental treatments are carried out by dentists or dental therapists is also influenced by funding systems. The UDA system is set to be replaced with a broader range of measures including prevention activity, ${ }^{14-16}$ for which the dually-qualified dental hygienist-therapist is well placed to deliver. ${ }^{16-18}$

A strength of this study is its comparison of two cohorts of TF trainees. The data collected in 2011 largely consolidates data collected in 2009. We were pleased to have input from eight of the nine 2008/09 trainees from whom we established records of employment history. Our contact with the 2009/10 cohort was limited, despite best efforts. Reasons for this might relate to their having had no prior contact with the evaluators.

\section{CONCLUSION}

The argument for DF training is well established and the TFT scheme offers comparable experience and education for dental therapists. The scheme allows the newly qualified therapist to gain confidence in their skills in a supportive environment. However, jobs for dental therapists are scarce and opportunity to use the full remit of duties remains limited. Although educational developments such as this TFT scheme are needed to embed the skills of the newly qualified dental therapist, in order to increase the employment opportunities for dental therapists training for leaders of the dental team is also required as well as structural changes to funding arrangements.

This work was supported by a grant from the Oxford and Wessex Postgraduate Dental Deanery. We wish to acknowledge the contribution made by all the individuals who gave their time to this study.

1. Evans C, Chestnutt I, Chadwick B L. The potential for delegation of clinical care in general dental practice. Br Dent J 2007; 203: 695-699.

2. General Dental Council. Scope of practice. London: GDC, 2009.

3. Jones G, Evans C, Hunter L. A survey of the workload of dental therapists/hygienist-therapists employed in primary care settings. Br Dent J 2008; 204: E5.

4. Turner S, Ross M K, lbbetson R J. Job satisfaction among dually qualified dental hygienist-therapists in UK primary care: a structural model. Br Dent J 2011; 210: E5

5. Brocklehurst $P R$, Tickle $M$. Is skill mix profitable in the current NHS dental contract in England? Br Dent J 2011; 210: 303-308.

6. Bullock A, Firmstone V. A professional challenge: the development of skill-mix in UK primary care dentistry. Health Serv Manage Res 2011 24: 190-195.

7. Bullock A D, Falcon H C, Mehra S, Stearns K. An evaluation of a vocational training scheme for dental therapists (TVT). Br Dent J 2010; 209: 295-300.

8. Committee of Postgraduate Dental Deans and Directors (COPDEND). Dental foundation training portfolio and assessment: user guide. Available at http://www.copdend.org/data/files/ Foundation/Denta|\%20Foundation\%20Training\%20 Portfolio\%20User\%20Guide\%5B1\%5D.pdf (accessed March 2013).

9. Firmstone V, Bullock A, Frame J. Dental therapists in the West Midlands: a study of educational needs and teamwork issues in primary care dentistry. Final report. Birmingham: University of Birmingham, 2009.

10. Jones G, Devalia R, Hunter L. Attitudes of genera dental practitioners in Wales towards employing dental hygienist-therapists. Br Dent J 2007; 203: E19.

11. Newton J T, Gibbons D E. Vacant posts reported in dental practice: implications for human resource planning. Br Dent J 2002: 192: 37-39.

12. Gallagher J L, Wright D A. General dental practitioners' knowledge of and attitudes towards the employment of dental therapists in general practice. Br Dent J 2003; 194: 37-41.

13. Gibbons D E, Corrigan M, Newton J T. The working practices and job satisfaction of dental therapists: findings of a national survey. Br Dent $J$ 2000; 189: $435-438$

14. Department of Health. Equity and excellence: liberating the NHS. London: $\mathrm{DH}, 2010$.

15. Steele J. NHS dental services in England: an independent review led by Professor Jimmy Steele. London: DH, 2009.

16. Williams S A Bradley S, Godson J H, Csikar JI, Rowbotham J S. Dental therapy in the United Kingdom: part 3. Financial aspects of current working practices. Br Dent J 2009; 207: 477-483.

17. Dyer T, Robinson P. General health promotion in general dental practice - the involvement of the dental team. Part 2: a qualitative and quantitative investigation of the views of practice principals in South Yorkshire. Br Dent J 2006; 201: 45-51.

18. Nilchian F, Rodd H D, Robinson P G. Influences on dentists' decisions to refer paediatric patients to dental hygienists and therapists for fissure sealants: a qualitative approach. Br Dent J 2009; 207: E13. 